PERSPECTIVE

\title{
Neuroplastin in human cognition: review of literature and
} future perspectives

\author{
Katarina Ilic ${ }^{1}$, Kristina Mlinac-Jerkovic (D) ${ }^{1}$, Goran Sedmak $\mathbb{D}^{1}$, Ivana Rosenzweig ${ }^{2,3}$ and Svjetlana Kalanj-Bognar (D) ${ }^{\boxplus}$
}

(c) The Author(s) 2021

Synaptic glycoprotein neuroplastin is involved in synaptic plasticity and complex molecular events underlying learning and memory. Studies in mice and rats suggest that neuroplastin is essential for cognition, as it is needed for long-term potentiation and associative memory formation. Recently, it was found that some of the effects of neuroplastin are related to regulation of calcium homeostasis through interactions with plasma membrane calcium ATPases. Neuroplastin is increasingly seen as a key factor in complex brain functions, but studies in humans remain scarce. Here we summarize present knowledge about neuroplastin in human tissues and argue its genetic association with cortical thickness, intelligence, schizophrenia, and autism; specific immunolocalization depicting hippocampal trisynaptic pathway; potential role in tissue compensatory response in neurodegeneration; and high, almost housekeeping, level of spatio-temporal gene expression in the human brain. We also propose that neuroplastin acts as a housekeeper of neuroplasticity, and that it may be considered as an important novel cognition-related molecule in humans. Several promising directions for future investigations are suggested, which may complete our understanding of neuroplastin actions in molecular basis of human cognition.

Translational Psychiatry (2021)11:394; https://doi.org/10.1038/s41398-021-01509-1

\section{INTRODUCTION}

The quest for molecules crucially involved in molecular mechanisms of learning and memory has over the years been marred with limited success. To date, synaptic glycoprotein neuroplastin (Np), which belongs to a cell-adhesion molecule family, has been by and large marginalized in this quest. However, we propose that $\mathrm{Np}$ may be the very molecular candidate, which is linked specifically to memory formation and cognition in the human brain. Although important roles of $\mathrm{Np}$ in learning and memory have been demonstrated in rodents, its role in human physiology remains unclear and, so far, there has been no systematic attempt to collate and compare the available, albeit limited, data.

We here present the spatio-temporal gene expression of $\mathrm{Np}$ during the human lifespan, critically review the body of work on $\mathrm{Np}$ localization in the human central nervous system (CNS), and report all available published work to date on its expression in human tissues in different physiological and pathological conditions.

We further advocate its role in the CNS by discussing published genetic studies, which showed association of specific Np gene polymorphisms with cortical thickness and intellectual ability in adolescents, susceptibility to schizophrenia, and occurrence of neurodevelopmental disorders, e.g., autism [1-3]. We argue for its key role in the memory, by summarizing all available immunohistochemical data, which demonstrates specific immunolocalization of $\mathrm{Np}$ in adult human brain and in the trisynaptic hippocampal pathway $[4,5]$. Role of $\mathrm{Np}$ in neurodegeneration is also suggested by demonstrating its involvement in tissue reorganization in Alzheimer's disease (AD) [6], whereas its role in neurodevelopment and brain maturation is further argued by data analysis showing that the Np gene expression (NPTN) steadily increases from the prenatal period to adulthood when the expression is highest [7]. Finally, we hypothesize housekeeping role of $\mathrm{Np}$ in neuroplasticity, given its high level of expression in the CNS compared to other human brain genes in general.

We provide insight into exciting and promising perspectives of investigating synaptic protein $\mathrm{Np}$ as a novel human cognitionrelated molecule and highlight major discoveries related to its involvement in cognitive processes, from findings in rodents to most recent data with highest importance for the human brain.

\section{NEUROPLASTIN DISCOVERY, STRUCTURE, AND FUNCTIONS Brief overview of $\mathrm{Np}$ research in mice and rats: from initial finding of a new synaptic protein to determining its roles in synaptic plasticity \\ During the last two decades, several pivotal studies in rodents and rodent cell cultures have suggested potential $\mathrm{Np}$ functions as follows: regulation of structure and function of synapses; regulation of excitatory and inhibitory synapses ratio; neurite outgrowth; long-term potentiation (LTP) regulation and main- tenance of hippocampal CA1 synaptic plasticity; associative memory formation; cognitive deterioration; and tissue response following ischemic injury [1, 2, 8-18]. In-depth investigation of $\mathrm{Np}$}

\footnotetext{
${ }^{1}$ Croatian Institute for Brain Research, School of Medicine, University of Zagreb, Šalata12, 10000 Zagreb, Croatia. ${ }^{2}$ Sleep and Brain Plasticity Centre, Department of Neuroimaging, Institute of Psychiatry, Psychology and Neuroscience (loPPN), King's College London (KCL), Strand, London WC2R 2LS, UK. 'Sleep Disorders Centre, Guy's and St Thomas' Hospital, Great Maze Pond, London SE1 9RT, UK. ${ }^{凶}$ email: svjetlana.kalanj.bognar@mef.hr
} 
Table 1. List of abbreviations, terms, and information related to mouse, rat, and human neuroplastin gene and protein isoforms, available in literature.

Neuroplastin gene names (Gene abbreviation; gene ID; chromosome)

Mouse (Nptn, Sdrf1, Sdr1; 20320; chr8)

Rat (Nptn, Sdrf1, Sdr1;56064; chr9)

Human (NPTN, SDRF1, SDR1; 27020; chr15)
Neuroplastin 55 isoform names (abbreviations)

Glycoprotein 55 (gp55)

Neuroplastin 55 (Np55)

Neuroplastin $\alpha$ (Nptn $\alpha$; NPTN $\alpha)$

Stromal cell-derived factor receptor 1

(Sdfr1, SDFR1)

Stromal cell-derived receptor 1

(Sdr1, SDR1)

Stromal cell-derived receptor $1 \alpha(\mathrm{Sdr} 1 \alpha$, SDR1 $\alpha)$

\author{
Neuroplastin 65 isoform names \\ (abbreviations) \\ Glycoprotein 65 (gp65) \\ Neuroplastin 65 (Np65) \\ Neuroplastin $\beta$ (Nptn $\beta$; NPTN $\beta$ ) \\ Stromal cell-derived factor receptor 1 \\ (Sdfr1, SDFR1) \\ Stromal cell-derived receptor 1 \\ (Sdr1, SDR1) \\ Stromal cell-derived receptor $1 \beta$ (Sdr1 $\beta$, \\ SDR1 $\beta$ )
}

functions began with the characterization of two novel components of the brain synaptic subfraction, glycoproteins of $M_{\mathrm{r}} 65,000$ and 55,000, named glycoprotein 65 and glycoprotein 55, which were eventually annotated as brain-specific Np65 and ubiquitous Np55 isoform, respectively [19]. (Different annotations of Np found in literature are summarized in Table 1.) Genetic and structural features of $\mathrm{Np}$ have been characterized [20-22] and its functions thoroughly investigated by in vivo and in vitro approaches $[8,13,15-18]$.

Several studies indicate that $\mathrm{Np}$, in partnership with basigin, exerts some of its effect(s) by acting as an obligatory subunit of the plasma membrane calcium ATPase (PMCA), therefore regulating $\mathrm{Ca}^{2+}$ ion homeostasis [5, 23, 24]. Recently, Np effects on spinogenesis and excitatory/inhibitory synapse ratio are found to be most likely regulated via tumor necrosis factor receptor-associated factor 6 (TRAF6) [25]. The adaptor protein TRAF6 is known to be involved in maintenance of the immune system homeostasis, through protein-protein interactions and cellular signaling linked to receptor families such as Toll-like receptors (TLRs) [26]. This finding suggests much higher complexity of potential $\mathrm{Np}$ functions in vital cellular processes than initially foreseen. Additional observations suggested that Nps are related to nervous cell energy metabolism and tissue response to ischemic injury as follows: acting as chaperones of monocarboxylate transporter MCT2 [14]; being involved in tissue response following ischemic injury in rat forebrain [10]; ensuring hypothesized mechanisms of tissue recovery as Np-knockout (KO) mice have been found to be more susceptible to ischemic brain lesions [27].

Further aspect of molecular complexity and machineries underlying processes related to memory, learning, and cognition encompasses so far a well-recognized influence of neuronal membrane composition, organization, and dynamics on synaptic plasticity $[28,29]$. Our group reported that Np positioning within the neuronal membrane is highly sensitive on its particular membrane lipid environment in murine brain tissue [30]. Specifically, compositional changes of membrane glycosphingolipids-gangliosides alter $\mathrm{Np}$ gene and protein expression, as well its immunolocalization and distribution in the mouse hippocampus [30]. The finding that implies effects of membrane lipid composition on functionality of $\mathrm{Np}$ has been recently supported by a study describing specific rearrangements of $\mathrm{Np}$ and gangliosides upon chronic stress and aging in the rat hippocampus [31]. Most recently, $\mathrm{Np}$ has been shown to preferentially segregate within lipid rafts [32], neighboring with specific synaptic proteins that reside in rafts such as synaptophysin, GABA receptors, glutamate receptors, and PMCA [33]. Exact mechanism of action and signaling cascade triggered by $\mathrm{Np}$ is yet to be resolved; however, its intramembrane clustering with molecular partners involved in synaptic organization, neurotransmission, and ion homeostasis makes it at least an additional important factor in myriad of (patho)physiological events occurring on the neuronal cell surface. Undoubtedly, a research approach that combines investigation of cross-talk of various raft constituents involved in the regulation of membrane excitability, neurotransmission, and synaptic organization/plasticity, with an analysis of specific membrane lipid-protein interactions, should significantly contribute to understanding the complexity of molecular events related to cognition (Fig. 1).

\section{Np functions in rodent brain: observations from studies on mice with Np deficiency}

An invaluable tool in investigating $\mathrm{Np}$ functions was the genetically engineered mouse not expressing $N p[5,16,34,35]$. Data from studies of $\mathrm{Np}$-deficient mice showed that constitutive $\mathrm{Np} \mathrm{KOs} \mathrm{have} \mathrm{altered} \mathrm{hypothalamic-pituitary-adrenal} \mathrm{axis} \mathrm{corre-}$ lates, elevated corticosterone levels, and decreased corticotropinreleasing hormone [16]. Although gross anatomy of the nervous system showed no differences compared to wild type, they displayed reduced motor capabilities and aberrant swimming behavior, less anxious behavior in open-field and light/dark avoidance tests, altered social interactions, and depressive-like behavior [16]. Ablation of $\mathrm{Np}$ in adult mice induced retrograde amnesia for associative learning [16]. In contrast, Amuti et al. [35] and Li et al. [36] reported that Np65 KO mice showed increased anxiety-like behavior, enhanced hippocampal-dependent memory enhanced sociability, and reduced depressive-like behavior, downregulated serotonin, and enhanced adult neurogenesis. $\mathrm{Li}$ et al. [36] suggest that contrasts in their results are due to different genetic deletions in those two mouse models. However, both models clearly show indispensable $\mathrm{Np}$ role in specific neuronal circuitry related to cognition.

\section{$\mathrm{Np}$ and regulation of intracellular calcium concentration}

An important discovery of $\mathrm{Np}$-interacting molecular partners and functions came from a study utilizing selective deletion of $\mathrm{Np}$ in glutamatergic neurons $[5,16]$. The study revealed that neuronal $\mathrm{Np}$ is essential for the expression of PMCA, regulation of cytosolic $\mathrm{Ca}^{2+}$ levels, and normal circuit activity [5, 24]. Np is also expressed by cells of the immune system and it has been shown that Np-PMCA complexes are important modulators of T-cell activation [24].

Functional proteomic analysis confirmed that $\mathrm{Np}$ is indeed related to $P M C A$, by determining $\mathrm{Np}$ as the essential auxiliary subunit of PMCA [23]. PMCA is crucial in regulating cellular $\mathrm{Ca}^{2+}$ homeostasis in all eukaryotic cells [37]. Alternative splicing results in diversity of expression and localization of four PMCA paralogs (PMCA1-4) [38-41]. The human PMCA1 (hPMCA1)-Np complex has been structurally resolved by cryo-electron microscopy $[37,42]$. Without Np, hPMCA1-alone proteins are devoid of ATPase activity and it has been determined that a transmembrane helix of $\mathrm{Np}$ interacts with specific transmembrane hPMCA1 regions [37]. Thus, through specific interactions, $\mathrm{Np}$ regulates $\mathrm{Ca}^{2+}$-binding site accessibility of PMCA [37].

Keeping in mind that $\mathrm{Np}$ has been implicated in LTP, which depends on $\mathrm{Ca}^{2+}$ homeostasis, findings that $\mathrm{Np}$ also functions as 
Neurotransmission/binding of specific ligand?

*Activation of $\mathrm{Np}$ within synaptic membranes

*Clustering of Np with PMCA within lipid raft

* Regulation of calcium transport and membrane excitability

* Cellular signaling cascade activated by $\mathrm{Np}$ ?

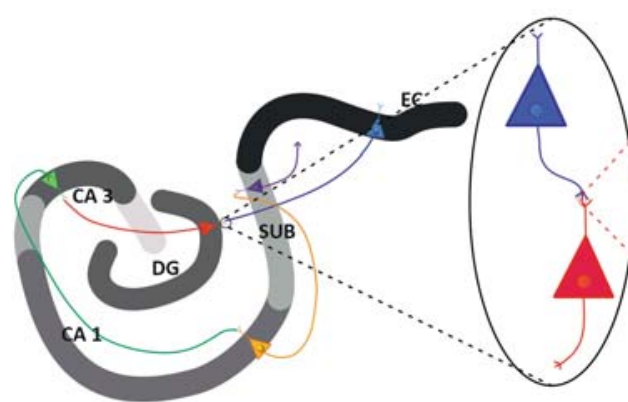

* Synaptic strength and plasticity

* Cognition

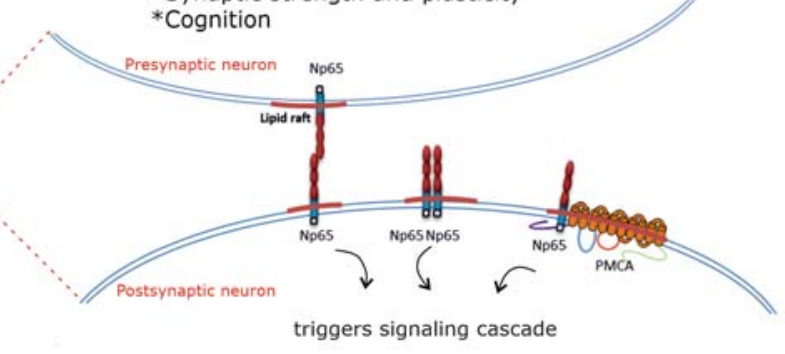

Fig. 1 Hypothethical representation of functionally associated lipid raft residents-neuroplastin and plasma membrane calcium ATPase -and their involvement in molecular basis of cognition. Np, neuroplastin; PMCA, plasma membrane calcium ATPase; CA, Cornu Ammonis; DG, dentate gyrus; SUB, subiculum; EC, entorhinal cortex.

an obligatory subunit of PMCA and in that way affects intracellular $\mathrm{Ca}^{2+}$ concentration provide additional proof of the outmost importance of this protein for the molecular mechanisms governing human cognitive processes.

$\mathrm{Np}$ in rodent model of obstructive sleep apnea: new perspectives for studying sleep and neuroplasticity in humans The pivotal role of sleep in the regulation, modulation, and the promotion of neuroplasticity of the brain has gained significant appreciation over the last few decades [43]. Bidirectional links between both the macro- and micro-architecture of sleep and neuroplasticity have demonstrated its crucial role in the recovery of cognitive functions [44, 45]. In view of this fundamental function of sleep, perhaps unsurprisingly, our group has recently demonstrated Np's involvement in recovery from one of the major sleep disorders, obstructive sleep apnea (OSA) [46], a condition linked to anxiety disorders, depression [47, 48], and AD [49-51], effectively with most of disorders that have so far also been linked with prominent $\mathrm{Np}$ plastic response. In our study of a rodent model of OSA, Np's expression appeared to be dependent on the TLR2 functionality [46]. Arguably, this might be reflective of a more important role in the recovery process in the absence of TLR2 and/ or of different mechanisms at play under control conditions. Either way, this finding debatably highlights the interlinking role for those two proteins.

In keeping with this emerging pattern of interlinking roles, the TLR2 receptors have been known to play an important role in $A D$ pathogenesis [52]. Similarly, several recent pivotal studies suggested abnormalities in TLRs, including the TLR2 system, might be playing an important role in the pathophysiology of depression and suicidal behavior [53], stress-induced neuroinflammation [54], elevated anxiety, and social avoidance [55]. To successfully address any potential temporo-anatomical mechanics of when, where, who, and how of this possible tripartite relationship and the interplay between sleep, $\mathrm{Np}$, and TLR2 system, future studies should be designed, which directly target the specific aspects of its purported cognitive and affective phenotypic aspects.

\section{NEUROPLASTIN IN HUMANS: TISSUE EXPRESSION, FUNCTIONS, AND DISORDERS \\ Np immunoreactivity pattern in the human brain}

The first study examining Np localization in the human brain showed a different pattern of immunohistochemical expression and distribution than in the rodent brain, explained to be related to species-specific functional diversity [4]. A more recent study by Herrera-Molina et al. [5] re-examined the data on Np65 immunohistochemical staining of selected human brain regions, with the main interest in human hippocampus, and analyzed the presence of $\mathrm{Np}$ isoforms in subcellular fractions derived from the human cortex. Not surprisingly, authors detected a much higher abundance of Np65 immunoreactivity in preparations of synaptic membranes, synaptic junctions, and postsynaptic densities compared to other subcellular fractions isolated from the human cortex. In the same study, Np65 immunoreactivity was found on neuronal cell bodies and fibers in the striatum (nucleus caudatus and putamen) and globus pallidus [5]. As stated before, Herrera-Molina et al. [5] were attentive to immunohistochemical expression and localization of $\mathrm{Np}$ in the human hippocampus and presented clear evidence of segregation of $\mathrm{Np}$ immunoreactivity in different hippocampal areas. More precisely, a distinct expression of $\mathrm{Np}$ was found in all major neuron-containing layers of the hippocampus-the stratum granulosum of the dentate gyrus (DG), the hilar part of the $C A 3$ region, the pyramidal cell layer of CA1 and CA2-3, and the cellular layers of subiculum. Np65 immunoreactivity was also detected in the molecular layer of DG, a layer containing apical dendrites of granule cells. In addition, low Np65 immunoreactivity was detected in the stratum plexiforme and within the hilar neuropil of DG. The entorhinal cortex, a major hippocampal input region, also showed specific Np immunolocalization, most prominently on glutamatergic pyramidal neurons of layer II, IV, and V. On the cellular level, Np65 reactivity was reported on membranes of the cell bodies of granule cells and pyramidal neurons, dendrites, as well as in punctate structures within the neuropil [5]. Thus, immunoreactivity of brain-specific Np65 was found to specifically delineate the trisynaptic pathway, known as the principal excitatory hippocampal pathway. It is of note that CA 1 and CA3 apical dendrites of the radiant and lacunar layer, as well as DG molecular and granular layer, are the targets of the perforant pathway composed of excitatory glutamatergic fibers. In addition, the synaptic output of the dentate granule cells includes formation of synapses with pyramidal neurons of the CA3 and the CA1-the specific connections involved in LTP. Axons of the pyramidal neurons of CA1 are considered to be the main hippocampal projections to subiculum and entorhinal cortex, and pyramidal layers of both subiculum and the entorhinal cortex show distinct $\mathrm{Np}$ signal. The layers known to be involved in internal and external regulatory circuits of the hippocampus-pyramidal cell layers of Cornu Ammonis (CA) and DG molecular layer containing interneurons show high and specific Np immunoreactivity [5]. Apart from the described 


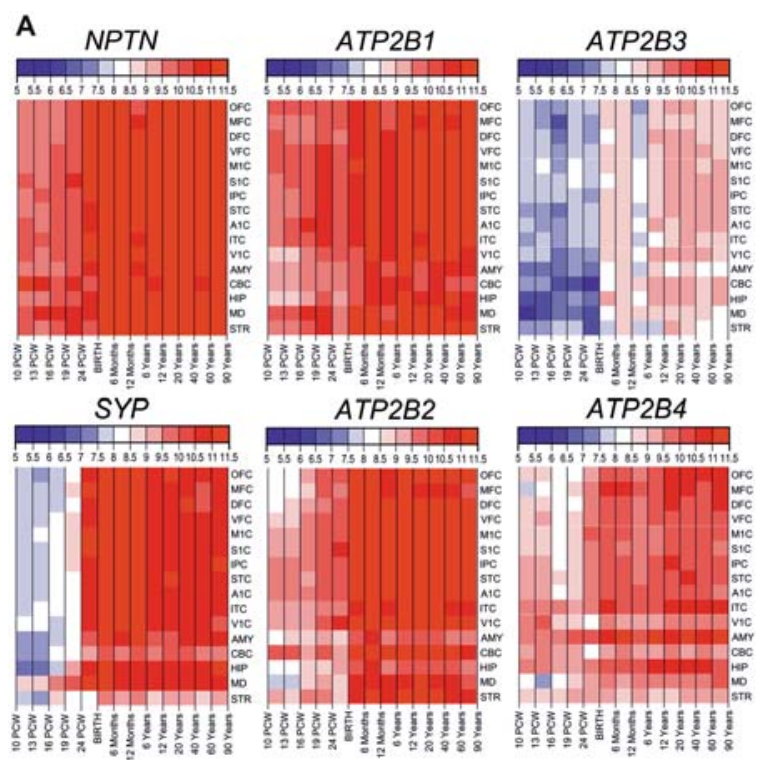

B
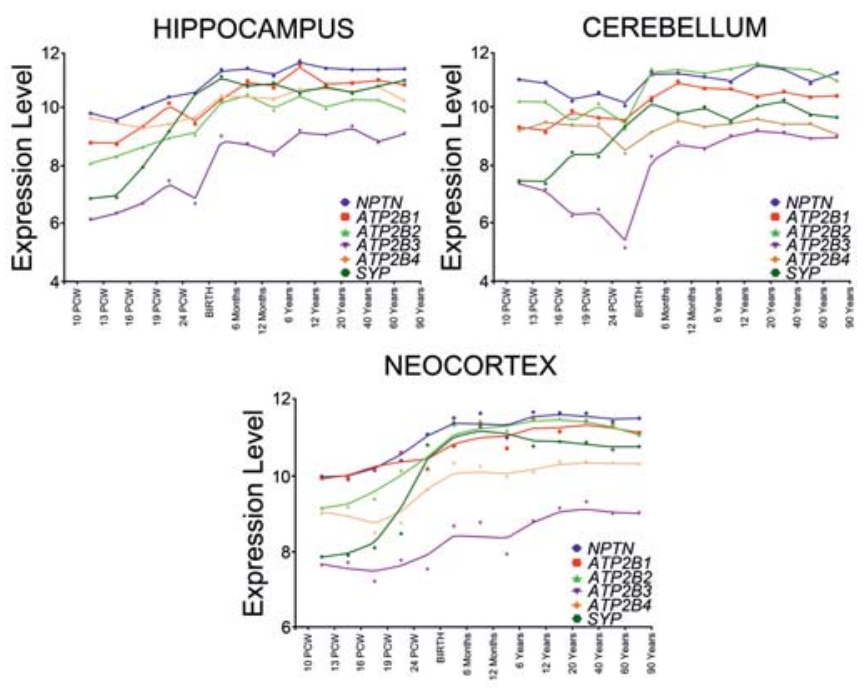

Fig. 2 Spatio-temporal gene expression of neuroplastin, plasma membrane calcium ATPase and synaptophysin in human brain. A Spatiotemporal transcriptome of neuroplastin, plasma membrane calcium ATPase isoforms 1-4, and synaptophysin in the human brain as extrapolated from refs. [7, 58]. Heatmaps depict gene expression values (color code key at the top of heatmap), in different brain areas and developmental periods. B Comparison of gene expression values for neuroplastin, plasma membrane calcium ATPase isoforms and synaptophysin in the human neocortex, hippocampus, and cerebellum during development, adulthood, and aging. Developmental periods are shown on the $x$-axis and level of expression on the $y$-axis. A1C, primary auditory (A1) cortex; AMY, amygdala; ATPB2[1-4], plasma membrane calcium ATPase isoforms 1-4; CBC, cerebellar cortex; DFC, dorsolateral prefrontal cortex; HIP, hippocampus; IPC, posterior inferior parietal cortex; ITC, inferior temporal cortex; M1C, primary motor (M1) cortex; MD, mediodorsal nucleus of the thalamus; MFC, medial prefrontal cortex; NPTN, neuroplastin; OFC, orbital prefrontal cortex; S1C, primary somatosensory (S1) cortex; STC, superior temporal cortex; STR, striatum; SYP, synaptophysin; V1C, primary visual (V1) cortex; VFC, ventrolateral prefrontal cortex.

expression of Np65 in the human hippocampus, it is clear that a much more detailed investigation of the cellular, regional, and temporal immunoreactivity pattern of $\mathrm{Np}$ in the human brain is needed. In addition, potential Np colocalization(s) with other known partners, which participate in molecular mechanisms underlying cognition and are clustered functionally within synaptic membranes, should be systematically examined. Not surprisingly, our unpublished observation indicates high immunofluorescence colocalization of $\mathrm{Np}$ and synaptophysin in major areas of adult human hippocampus (DG, CA1, and CA2/ $3)$, which corresponds with presumed functional association of these two synaptic proteins previously described in rat organotypic hippocampal slice cultures [56]. Apparently, utilization of modern high-resolution microscopy techniques may, in a short time, decipher the exact cellular and regional distribution of $\mathrm{Np}$ in the human brain. Such data along with findings of a great translational value from animal model studies will surely elucidate the extent and importance of $\mathrm{Np}$ actions in molecular events underlying human cognition.

\section{Spatio-temporal transcriptomic data for Np, PMCA, and synaptophysin in the human brain}

Data on $\mathrm{Np}$ immunoreactivity pattern in the human brain are so far limited to the hippocampus and striatum. Our group has recently determined spatio-temporal gene expression of Np (NPTN) utilizing microarray database of healthy human brain (GEO accession GSE 25219, Human Exon 1.0 ST Array), as previously described [7]. Based on our observation on immunohistochemical colocalization of $\mathrm{Np}$ and synaptophysin in adult human hippocampus, and characterized functional interaction of Np and PMCA [23, 24], we have been interested as well in the expression pattern of genes coding for four PMCA isoforms and synaptophysin (ATP2B1, ATP2B2, ATP2B3, ATP2B4, and SYP). Transcriptomic analysis was performed in the hippocampus, cerebellum, and neocortex from 10 postconceptional weeks to
82 years of life, using a described method [57]. All six genes were expressed in all analyzed regions and time periods, and exhibited similar pattern of expression-lower levels of expression during prenatal period (Fig. 2A) and increase of expression during childhood, with the highest levels of expression during adulthood. The NPTN expression was higher than ATP2B and SYP in all analyzed brain regions and developmental periods (Fig. 2B). The only exceptions observed were SYP expression in the neocortex, hippocampus, and cerebellum, and ATP2B2 expression in the cerebellum, reaching NPTN expression level at birth and mainly retaining the same expression level as NPTN during early childhood and adulthood (Fig. 2B). ATP2B3 exhibited the lowest levels of expression in all analyzed regions and periods (Fig. 2B).

It is interesting to note that here the analyzed genes coding for $\mathrm{Np}$, four PMCA isoforms, and synaptophysin exhibited very high levels of expression in adulthood compared to other genes in the human brain [7], even proportional to the expression of certain well-known housekeeping genes. Presented spatio-temporal transcriptomic analysis of synaptophysin expression pattern corresponds perfectly to the so far well-described functions of this synaptic protein in developing and adult human brain. The exact significance of the observed housekeeping level of particularly NPTN in practically all regions of the human brain has yet to be determined. We assume that $\mathrm{Np}$ gene expression pattern data strongly support its indispensable role in crucial cellular processes in the human nervous system, such as neural migration, synaptogenesis, neurotransmission, and establishing of neural circuitries.

Np genetic variations and immunohistochemical expression in relationship with cognitive functions, neuropsychiatric disorders, and neurodegeneration

A study investigating the correlation of cortical thickness with intellectual ability in adolescents, as well as contribution of 
Table 2. Neuroplastin in human tissues.

\begin{abstract}
Main finding
Neuroplastin is among the deregulated genes in mammary breast cancer models and in human breast cancer.
\end{abstract}

Higher neuroplastin expression may promote tumor invasion and/or metastatic potential in breast carcinomas.

Neuroplastin expression in human brain is detected in the cortex and cerebellum, but pattern differs from rodent brain.

Single-nucleotide polymorphisms (SNPs) confer to genetic susceptibility to schizophrenia.

Neuroplastin is deleted in chromosomal microdeletion and inverted duplication in a patient with autism and patients with developmental delay.

Neuroplastin is upregulated in olfactory bulb-derived neural stem cells and human embryonic stem cells.

Neuroplastin SNPs are linked to cortical thickness and intelligence in adolescents.

Neuroplastin colocalizes with extracellular matrix metalloproteinase inducer S100A8 and this interaction is important for keratinocyte proliferation ( $\mathrm{Np}$ as S100A8/A9 receptor).

Neuroplastin immunoreactivity delineates hippocampal sublayers that are involved in trisynaptic pathway.

Neuroplastin has the ability to induce cancer-related cellular events, such as growth, motility, and invasiveness in lung cancer cells as S100A8/A9 receptor.

Neuroplastin expression is higher in early stages of Alzheimer's disease in hippocampus than in control hippocampi, and it decreases with the duration of the disease.

\section{Detected on gene or protein level \\ NPTN (SDFR1) gene overexpression}

NPTN $(\mathrm{Np} \beta)$ protein overexpression (detected by proteomic identification of affinity selected tumor proteins)

$\mathrm{Np}$ protein expression (immunohistochemistry)

SNP in NPTN gene promoter region

NPTN gene deletion

NPTN gene overexpression

SNP in NPTN gene

Np65 (Np $\beta)$ gene and protein expression investigated

Np65 protein expression (immunohistochemistry)

Np65 (Np $\beta)$ gene and protein (detected by immunohistochemistry) expression investigated

Np65 protein expression (immunohistochemistry)

\section{Publication \\ Rodriguez-Pinto et al. [67]}

Rodriguez-Pinto et al. [67]

Bernstein et al. [4]

Saito et al. [1]

Filipek et al. [61], Sharp et al. [62], Klopocki et al. [63], Smith et al. [3]

Marei et al. [68]

Desrivieres et al. [2]

Sakaguchi et al. [69]

Herrera-Molina et al. [5]

Sumardika et al. [70],

Tomonobu et al. [71]

llic et al. [6] individual genes to those parameters, pinpointed $\mathrm{Np}$ as a protein whose single-nucleotide polymorphisms affect both [2]. Changes in cortical thickness in the left hemisphere have been found to correlate with performance of children on a test of general verbal intellectual functioning [58]. Comparison of estimates of genetic effects in the left and right hemispheres indicates that the language-dominant left cerebral cortex may be under stronger genetic control than the right cortex [59]. Association of one NPTN polymorphism (rs7171755) with effects on cortical thickness was found to be region-specific, with the most significant overall influences on the left temporal, frontal, and parietal lobes [2].

Following their publication on increased Np expression in rats after exposure to phencyclidine and methamphetamine, drugs known to induce long-lasting psychotic states [60], Saito et al. [1] investigated whether variations in $\mathrm{Np}$ gene confer genetic susceptibility to schizophrenia. In a study that included 200 patients with schizophrenia and 278 healthy volunteers, variations in SNPs in the $5^{\prime}$ upstream regions of NPTN were found, which may confer to genetic susceptibility to schizophrenia. In addition, a haplotype that was more frequently found in controls than patients with schizophrenia could be associated with mitigating the onset risk of schizophrenia, as its reduced transcriptional activity may interfere with excessive homophilic NPTN-NPTN interaction [1].

Furthermore, in a review by Smith et al. [3], $\mathrm{Np}$ is identified as a candidate implicated in the development of autism and neurodevelopmental disorders in general. The authors evaluate broad genetic mechanisms underlying genomic imbalances in autism, e.g., how would altered gene dosage and structure impact neurodevelopment and contribute to the risk for autism. The data regarding $\mathrm{Np}$ relies on an earlier study performed by the authors [61] in conjunction with two other studies from 2007 [62].
Taken together, the data show that $\mathrm{Np}$ was deleted in chromosomal microdeletion (15q24) in a patient with autism [61] and five patients exhibiting mild/moderate developmental delay $[62,63]$.

Genetic studies are a powerful tool in identifying underlying contributors to various complex pathological states. Therefore, these independent studies analyzing intellectual ability, schizophrenia, and autism, all pointing to $\mathrm{Np}$, strongly indicate that $\mathrm{Np}$ should be considered in the evaluation of root causes of different neuropsychiatric disorders.

In addition to the cited genetic studies related to potential roles of $\mathrm{Np}$ in human neuropsychiatric disorders, there has been only one publication dealing with immunohistochemical analysis of $\mathrm{Np}$ expression in neuropathologically changed human brain tissue. The study was performed by our group-we analyzed immunohistological distribution of Np in human hippocampus affected by AD and reported increased Np65 immunoreactivity compared to age- and gender-matched samples in cases with disease duration shorter than 4 years. Np65 immunoreactivity was significantly increased in the DG, in particular on the dendrites of granule cells, pyramidal neurons of $\mathrm{CA} 2 / 3$, and subiculum. Changes in the expression were related to the progression of disease, as $\mathrm{Np}$ expression was decreased in all areas with prolonged duration of the disease ( $>5$ years). We suggested that Np65 is involved in tissue reorganization and may be considered as a potential molecular marker of plasticity response in the early phase of $A D$ pathological neurodegeneration cascade [6].

\section{Np expression and function in human non-neural tissues}

Besides studies dealing with brain-specific Np isoform (Np65), findings from investigation of non-neural human tissues 
demonstrate that $\mathrm{Nps}$ are very likely involved in vital cellular processes such as cell proliferation and differentiation. Available data on $\mathrm{Np}$ expression in human tissues and different malignancies, summarized in Table 2, are supportive of suggested various actions of $\mathrm{Np}$ in human tissues according to previously published roles of other cell-adhesion molecules in intercellular interactions and communication [64-71]. Current knowledge on $\mathrm{Np}$ in rodents and humans implies actions potentially broader than the ones related to synaptic plasticity and these may be specifically associated with more ubiquitously expressed Np55 isoform. We propose that Np55 is involved in cellular housekeeping/"hardware" maintenance and participates in short-term cellular responses to numerous stimuli, whereas Np65 has specialized, sophisticated, cognition-related roles in differentiated neuronal populations. Thus, it will be of particular interest to search for, most probably, very diverse effects of each of the two $\mathrm{Np}$ isoforms in mammalian brain tissue but also their presumed cooperative actions in different patho(physiological) conditions.

\section{CONCLUSIONS AND FUTURE RESEARCH PROSPECTS}

Arguably, the complexity of molecular and cellular phenomena related to human cognition by far outstrips the effects of just one molecule. However, we propose that one molecule can make a significant difference-even in such a structurally intricate and functionally sophisticated system as the human brain. We suggest that synaptic protein $\mathrm{Np}$ should be considered as an important cognition-related molecule, which is supported by preliminary insights gained from here reported studies in the human brain. $\mathrm{Np}$ 's involvement in molecular mechanism of learning, memory, and cognition, has been undoubtedly confirmed in outlined studies in rodent brain and cell cultures. More recent data referring to $\mathrm{Np}$ gene and protein expression in the human brain strongly indicate its significant role in neuroplasticity and molecular events underlying cognitive processes, as well as its involvement in disorders accompanied with altered cognitive performance.

To more authoritatively ascertain the role for $\mathrm{Np}$ in the human brain, future studies will need to clarify the following: (1) structural features of $\mathrm{Np}$ in human tissues and probable effects of tissueand species-specific glycosylation patterns on its functions; (2) membrane dynamics in physiological and pathophysiological conditions with emphasis on tracking the cross-talk of $\mathrm{Np}$ with other molecular partners within its specific (intra)membrane environment; (3) signaling mechanism of its cellular effects; (4) systematic mapping of its gene and protein expression in the human brain during critical periods of development, maturation, and aging; (5) cell types and neuronal circuitries marked by $\mathrm{Np}$; (6) mechanisms underlying its expression in response to different (patho)physiological stimuli, related to its hypothesized role as a housekeeper of neuroplasticity.

From its initial discovery 30 years ago, $\mathrm{Np}$ has emerged as a likely significant factor involved in fine-tuning neuroplasticity and molecular events underlying cognitive processes in humans. We expect that $\mathrm{Np}$ research will be intensified in the future, shedding more light into the molecular mechanisms crucial for human cognition.

\section{REFERENCES}

1. Saito A, Fujikura-Ouchi Y, Kuramasu A, Shimoda K, Akiyama K, Matsuoka H, et al. Association study of putative promoter polymorphisms in the neuroplastin gene and schizophrenia. Neurosci Lett. 2007;411:168-173.

2. Desrivières $S$, Lourdusamy $A$, Tao $C$, Toro $R$, Jia $T$, Loth $E$, et al. Single nucleotide polymorphism in the neuroplastin locus associates with cortical thickness and intellectual ability in adolescents. Mol Psychiatry. 2015;20:263-274.

3. Smith M, Spence MA, Flodman P. Nuclear and mitochondrial genome defects in autisms. Ann N Y Acad Sci. 2009;1151:102-132.
4. Bernstein HG, Smalla KH, Bogerts B, Gordon-Weeks PR, Beesley PW, Gundelfinger $E D$, et al. The immunolocalization of the synaptic glycoprotein neuroplastin differs substantially between the human and the rodent brain. Brain Res. 2007;1134:107-112.

5. Herrera-Molina R, Mlinac-Jerkovic K, llic K, Stöber F, Vemula SK, Sandoval M, et al. Neuroplastin deletion in glutamatergic neurons impairs selective brain functions and calcium regulation: implication for cognitive deterioration. Sci Rep. 2017;7:7273.

6. Ilic K, Mlinac-Jerkovic K, Jovanov-Milosevic N, Simic G, Habek N, Bogdanovic N, et al. Hippocampal expression of cell-adhesion glycoprotein neuroplastin is altered in Alzheimer's disease. J Cell Mol Med. 2019;23:1602-1607.

7. Kang HJ, Kawasawa YI, Cheng F, Zhu Y, Xu X, Li M, et al. Spatio-temporal transcriptome of the human brain. Nature. 2011;478:483-489.

8. Herrera-Molina R, Sarto-Jackson I, Montenegro-Venegas $C$, Heine $M$, Smalla $\mathrm{KH}$, Seidenbecher $\mathrm{Cl}$, et al. Structure of excitatory synapses and GABAA receptor localization at inhibitory synapses are regulated by neuroplastin-65. J Biol Chem. 2014;289:8973-8988.

9. Sarto-Jackson I, Milenkovic I, Smalla KH, Gundelfinger ED, Kaehne T, Herrera-Molina $\mathrm{R}$, et al. The cell adhesion molecule neuroplastin- 65 is a novel interaction partner of gamma-aminobutyric acid type A receptors. J Biol Chem. 2012;287:14201-14214.

10. Beesley $P$, Kraus $M$, Parolaro $N$. The neuroplastins: multifunctional neuronal adhesion molecules-involvement in behaviour and disease. Adv Neurobiol. 2014;8:61-89.

11. Beesley PW, Herrera-Molina R, Smalla KH, Seidenbecher C. The neuroplastin adhesion molecules: key regulators of neuronal plasticity and synaptic function. J Neurochem 2014;131:268-283.

12. Empson RM, Buckby LE, Kraus M, Bates KJ, Crompton MR, Gundelfinger ED, et al. The cell adhesion molecule neuroplastin- 65 inhibits hippocampal long-term potentiation via a mitogen-activated protein kinase p38-dependent reduction in surface expression of GluR1-containing glutamate receptors. J Neurochem. 2006;99:850-860.

13. Smalla KH, Matthies $H$, Langnäse $K$, Shabir S, Böckers TM, Wyneken U, et al. The synaptic glycoprotein neuroplastin is involved in long-term potentiation at hippocampal CA1 synapses. Proc Natl Acad Sci USA. 2000;97:4327-4332.

14. Wilson MC, Kraus M, Marzban H, Sarna JR, Wang Y, Hawkes R, et al. The neuroplastin adhesion molecules are accessory proteins that chaperone the monocarboxylate transporter MCT2 to the neuronal cell surface. PLoS ONE. 2013;8: e78654.

15. Owczarek S, Soroka V, Kiryushko D, Larsen MH, Yuan Q, Sandi C, et al. Neuroplastin65 and a mimetic peptide derived from its homophilic binding site modulate neuritogenesis and neuronal plasticity. J Neurochem. 2011;117:984-994.

16. Bhattacharya S, Herrera-Molina R, Sabanov V, Ahmed T, Iscru E, Stöber F, et al. Genetically induced retrograde amnesia of associative memories after neuroplastin ablation. Biol Psychiatry. 2017;81:124-135.

17. Owczarek S, Kiryushko D, Larsen MH, Kastrup JS, Gajhede M, Sandi C, et al. Neuroplastin-55 binds to and signals through the fibroblast growth factor receptor. FASEB J. 2010;24:1139-1150.

18. Owczarek S, Berezin V. Neuroplastin: cell adhesion molecule and signaling receptor. Int J Biochem Cell Biol. 2012;44:1-5.

19. Hill IE, Selkirk CP, Hawkes RB, Beesley PW. Characterization of novel glycoprotein components of synaptic membranes and postsynaptic densities, gp65 and gp55, with a monoclonal antibody. Brain Res. 1988;461:27-43.

20. Langnaese K, Mummery R, Gundelfinger ED, Beesley PW. Immunoglobulin superfamily members gp65 and gp55: tissue distribution of glycoforms. FEBS Lett. 1998;429:284-288.

21. Langnaese K, Seidenbecher C, Wex H, Seidel B, Hartung K, Appeltauer U, et al. Protein components of a rat brain synaptic junctional protein preparation. Brain Res Mol Brain Res. 1996;42:118-122.

22. Shirozu M, Tada H, Tashiro K, Nakamura T, Lopez ND, Nazarea M, et al. Characterization of novel secreted and membrane proteins isolated by the signal sequence trap method. Genomics. 1996;37:273-280.

23. Schmidt N, Kollewe A, Constantin CE, Henrich S, Ritzau-Jost A, Bildl W, et al. Neuroplastin and basigin are essential auxiliary subunits of plasma membrane $\mathrm{Ca}$ $(2+)$-ATPases and key regulators of $\mathrm{Ca}(2+)$ clearance. Neuron. 2017;96:827-838.

24. Korthals M, Langnaese K, Smalla KH, Kähne T, Herrera-Molina R, Handschuh J, et al. A complex of neuroplastin and plasma membrane $\mathrm{Ca}(2+)$ ATPase controls $\mathrm{T}$ cell activation. Sci Rep. 2017;7:8358.

25. Vemula SK, Malci A, Junge L, Lehmann AC, Rama R, Hradsky J, et al. The interaction of TRAF6 with neuroplastin promotes spinogenesis during early neuronal development. Front Cell Dev Biol. 2020;8:579513.

26. Walsh MC, Lee J, Choi Y. Tumor necrosis factor receptor- associated factor 6 (TRAF6) regulation of development, function, and homeostasis of the immune system. Immunol Rev. 2015;266:72-92.

27. Hu Y, Zhan Q, Zhang H, Liu X, Huang L, Li H, et al. Increased susceptibility to ischemic brain injury in neuroplastin 65 -deficient mice likely via glutamate excitotoxicity. Front Cell Neurosci. 2017;11:110. 
28. Sonnino S, Mauri L, Ciampa MG, Prinetti A. Gangliosides as regulators of cell signaling: ganglioside-protein interactions or ganglioside-driven membrane organization? J Neurochem. 2013;124:432-435.

29. Huston JP, Kornhuber J, Mühle C, Japtok L, Komorowski M, Mattern C, et al. A sphingolipid mechanism for behavioral extinction. J Neurochem. 2016;137:589-603.

30. Mlinac K, Jovanov Milosevic N, Heffer M, Smalla KH, Schnaar RL, Kalanj Bognar S. Neuroplastin expression in the hippocampus of mice lacking complex gangliosides. J Mol Neurosci. 2012;48:161-6.

31. Balog M, Blažetić S, Ivić V, Labak I, Krajnik B, Marin R, et al. Disarranged neuroplastin environment upon aging and chronic stress recovery in female Sprague Dawley rats. Eur J Neurosci. 2021;00:1-17.

32. Mlinac-Jerkovic K, llic K, Zjalić M, Mandić D, Debeljak Z, Balog M, et al. Who's in, who's out? Re-evaluation of lipid raft residents. J Neurochem. 2021; https://doi. org/10.1111/jnc.15446.

33. Eckert GP. Manipulation of lipid rafts in neuronal. Cells Open Biol J 2010;3:8-38.

34. Li H, Zeng J, Huang L, Wu D, Liu L, Liu Y, et al. Microarray analysis of gene expression changes in neuroplastin 65-knockout mice: implications for abnormal cognition and emotional disorders. Neurosci Bull. 2018;34:779-788.

35. Amuti S, Tang Y, Wu S, Liu L, Huang L, Zhang H, et al. Neuroplastin 65 mediates cognitive functions via excitatory/inhibitory synapse imbalance and ERK signal pathway. Neurobiol Learn Mem. 2016;127:72-83.

36. Li H, Liu Y, Gao X, Liu L, Amuti S, Wu D, et al. Neuroplastin 65 modulates anxietyand depression-like behavior likely through adult hippocampal neurogenesis and central 5-HT activity. FEBS J. 2019;286:3401-3415.

37. Gong D, Chi X, Ren K, Huang G, Zhou G, Yan N, et al. Structure of the human plasma membrane $\mathrm{Ca}(2+)$-ATPase 1 in complex with its obligatory subunit neuroplastin. Nat Commun. 2018;9:3623.

38. Strehler EE. Plasma membrane calcium ATPases as novel candidates for therapeutic agent development. J Pharm Pharm Sci. 2013;16:190-206.

39. Stahl WL, Keeton TP, Eakin TJ. The plasma membrane $\mathrm{Ca}(2+)$-ATPase mRNA isoform PMCA 4 is expressed at high levels in neurons of rat piriform cortex and neocortex. Neurosci Lett. 1994;178:267-70.

40. Burette A, Rockwood JM, Strehler EE, Weinberg RJ. Isoform-specific distribution of the plasma membrane Ca2+ ATPase in the rat brain. J Comp Neurol. 2003:467:464-476.

41. Burette AC, Strehler EE, Weinberg RJ. A plasma membrane Ca2+ ATPase isoform at the postsynaptic density. Neuroscience 2010;169:987-993.

42. Go CK, Soboloff J. Hold the door: hPMCA1/neuroplastin interactions regulate $\mathrm{Ca}(2$ +)-binding site accessibility. Cell Calcium. 2018;76:135-136.

43. Tononi G, Cirelli C. Sleep and the price of plasticity: from synaptic and cellular homeostasis to memory consolidation and integration. Neuron 2014;81: 12-34.

44. Mensen A, Pigorini A, Facchin L, Schöne C, D'Ambrosio S, Jendoubi J, et al. Sleep as a model to understand neuroplasticity and recovery after stroke: observational, perturbational and interventional approaches. J Neurosci Methods. 2019;313:37-43.

45. Polsek D, Gildeh N, Cash D, Winsky-Sommerer R, Williams S, Turkheimer F, et al. Obstructive sleep apnoea and Alzheimer's disease: in search of shared pathomechanisms. Neurosci Biobehav Rev. 2018;86:142-149.

46. Polsek D, Cash D, Veronese M, llic K, Wood TC, Milosevic M, et al. The innate immune Toll-like receptor-2 modulates the depressogenic and anorexiolytic neuroinflammatory response in obstructive sleep apnoea. Sci Rep. 2020;10:11475.

47. Khazaie H, Veronese M, Noori K, Emamian F, Zarei M, Ashkan K, et al. Functional reorganization in obstructive sleep apnoea and insomnia: a systematic review of the resting-state fMRI. Neurosci Biobehav Rev. 2017;77:219-231.

48. Rosenzweig I, Glasser M, Polsek D, Leschziner GD, Williams SC, Morrell MJ. Sleep apnoea and the brain: a complex relationship. Lancet Respir Med. 2015;3:404-414.

49. Emamian F, Khazaie $\mathrm{H}$, Tahmasian M, Leschziner GD, Morrell MJ, Hsiung GY, et al. The association between obstructive sleep apnea and Alzheimer's disease: a meta-analysis perspective. Front Aging Neurosci. 2016;8:78.

50. Bubu OM, Pirraglia E, Andrade AG, Sharma RA, Gimenez-Badia S, Umasabor-Bubu $\mathrm{OQ}$, et al. Obstructive sleep apnea and longitudinal Alzheimer's disease biomarker changes. Sleep. 2019;42:zsz048.

51. Sharma RA, Varga AW, Bubu OM, Pirraglia E, Kam K, Parekh A, et al. Obstructive sleep apnea severity affects amyloid burden in cognitively normal elderly. A longitudinal study. Am J Respir Crit Care Med. 2018;197:933-943.

52. Rangasamy SB, Jana M, Roy A, Corbett GT, Kundu M, Chandra S, et al. Selective disruption of TLR2-MyD88 interaction inhibits inflammation and attenuates Alzheimer's pathology. J Clin Invest. 2018;128:4297-4312.

53. Pandey GN, Rizavi HS, Bhaumik R, Ren X. Innate immunity in the postmortem brain of depressed and suicide subjects: role of Toll-like receptors. Brain Behav Immun. 2019;75:101-111.

54. Gárate I, Garcia-Bueno B, Madrigal JL, Caso JR, Alou L, Gomez-Lus ML, et al. Stressinduced neuroinflammation: role of the Toll-like receptor-4 pathway. Biol Psychiatry. 2013;73:32-43.
55. Nie X, Kitaoka S, Tanaka K, Segi-Nishida E, Imoto Y, Ogawa A. et al. The innate immune receptors TLR2/4 mediate repeated social defeat stress-induced social avoidance through prefrontal microglial activation. Neuron. 2018;99:464-79.e7.

56. Buckby LE, Mummery R, Crompton MR, Beesley PW, Empson RM. Comparison of neuroplastin and synaptic marker protein expression in acute and cultured organotypic hippocampal slices from rat. Brain Res Dev Brain Res. 2004;150:1-7.

57. Sedmak $G$, Jovanov-Milošević $N$, Puskarjov $M$, Ulamec $M$, Krušlin B, Kaila $K$, et al. Developmental expression patterns of $\mathrm{KCC} 2$ and functionally associated molecules in the human brain. Cereb Cortex. 2016;26:4574-4589.

58. Sowell ER, Thompson PM, Leonard CM, Welcome SE, Kan E, Toga AW. Longitudinal mapping of cortical thickness and brain growth in normal children. J. Neurosci. 2004;24:8223-8231.

59. Yoon U, Fahim C, Perusse D, Evans AC. Lateralized genetic and environmental influences on human brain morphology of 8-year-old twins. Neuroimage 2010:53:1117-1125.

60. Ouchi Y, Kubota Y, Kuramasu A, Watanabe T, Ito $C$. Gene expression profiling in whole cerebral cortices of phencyclidine- or methamphetamine-treated rats. Brain Res Mol Brain Res. 2005;140:142-149.

61. Filipek PA, Juranek J, Smith M, Mays LZ, Ramos ER, Bocian M, et al. Mitochondrial dysfunction in autistic patients with $15 q$ inverted duplication. Ann Neurol. 2003;53:801-804.

62. Sharp AJ, Selzer RR, Veltman JA, Gimelli S, Gimelli G, Striano P, et al. Characterization of a recurrent $15 q 24$ microdeletion syndrome. Hum Mol Genet. 2007;16:567-72.

63. Klopocki E, Graul-Neumann LM, Grieben U, Tönnies H, Ropers HH, Horn D, et al. A further case of the recurrent $15 \mathrm{q} 24$ microdeletion syndrome, detected by array CGH. Eur J Pediatr. 2008;167:903-908.

64. Fields RD, Stevens-Graham B. New insights into neuron-glia communication. Science 2002;298:556-562.

65. Foty RA, Steinberg MS. Cadherin-mediated cell-cell adhesion and tissue segregation in relation to malignancy. Int J Dev Biol. 2004;48:397-409.

66. Giagtzoglou N, Ly CV, Bellen HJ. Cell adhesion, the backbone of the synapse: "vertebrate" and "invertebrate" perspectives. Cold Spring Harb Perspect Biol. 2009;1:a003079.

67. Rodriguez-Pinto D, Sparkowski J, Keough MP, Phoenix KN, Vumbaca F, Han DK et al. Identification of novel tumor antigens with patient-derived immuneselected antibodies. Cancer Immunol Immunother. 2009;58:221-234.

68. Marei HE, Ahmed AE, Michetti F, Pescatori M, Pallini R, Casalbore P, et al. Gene expression profile of adult human olfactory bulb and embryonic neural stem cell suggests distinct signaling pathways and epigenetic control. PLoS ONE. 2012;7: e33542.

69. Sakaguchi $M$, Yamamoto $M$, Miyai $M$, Maeda T, Hiruma J, Murata $H$, et al. Identification of an S100A8 receptor neuroplastin- $\beta$ and its heterodimer formation with EMMPRIN. J Invest Dermatol. 2016;136:2240-2250.

70. Sumardika IW, Chen Y, Tomonobu N, Kinoshita R, Ruma I, Sato H, et al. Neuroplastin- $\beta$ mediates S100A8/A9-induced lung cancer disseminative progression. Mol Carcinog. 2019;58:980-995.

71. Tomonobu N, Kinoshita R, Sakaguchi M. S100 soil sensor receptors and molecular targeting therapy against them in cancer metastasis. Transl Oncol. 2020;13:100753.

\section{ACKNOWLEDGEMENTS}

This work was supported by Croatian Science Foundation (CSF), "NeuroReact" project (IP 2016-06-8636, PI:SKB), and the Scientific Centre of Excellence for Basic, Clinical, and Translational Neuroscience (project "Experimental and clinical research of hypoxic ischemic damage in perinatal and adult brain" GA KK 0111010007 funded by the European Union through the European Regional Development Fund).

\section{COMPETING INTERESTS}

The authors declare no competing interests.

\section{ADDITIONAL INFORMATION}

Correspondence and requests for materials should be addressed to S.K-B.

Reprints and permission information is available at http://www.nature.com/ reprints

Publisher's note Springer Nature remains neutral with regard to jurisdictional claims in published maps and institutional affiliations. 
(c) (i) Open Access This article is licensed under a Creative Commons Attribution 4.0 International License, which permits use, sharing, adaptation, distribution and reproduction in any medium or format, as long as you give appropriate credit to the original author(s) and the source, provide a link to the Creative Commons license, and indicate if changes were made. The images or other third party material in this article are included in the article's Creative Commons license, unless indicated otherwise in a credit line to the material. If material is not included in the article's Creative Commons license and your intended use is not permitted by statutory regulation or exceeds the permitted use, you will need to obtain permission directly from the copyright holder. To view a copy of this license, visit http://creativecommons. org/licenses/by/4.0/.

() The Author(s) 2021 